\title{
COMT polymorphism influences decrease of ovarian follicles and emerges as a predictive factor for premature ovarian insufficiency
}

\author{
Emerson Barchi Cordts ${ }^{1}$, Monise Castro Santos ${ }^{1}$, Carla Peluso ${ }^{1}$, Erika Azuma Kayaki ${ }^{1}$, Bianca Bianco ${ }^{1,2^{*}}$,
} Caio Parente Barbosa ${ }^{1}$ and Denise Maria Christofolini ${ }^{1}$

\begin{abstract}
Background: Estrogens are important factors in the female reproductive functions and are processed by a number of enzymes along their metabolic pathway. The COMT gene constitutes a crucial element in estrogen metabolism and is assumed to be involved in the development of Premature Ovarian Insufficiency (POI). This study aimed to determine whether the presence of the COMT Val/Met polymorphism (rs4680) is associated to the risk of developing POI.

Findings: In this case-control study, we evaluated 96 infertile women with POI and 120 fertile women as controls, after obtaining a detailed history of the disease and follicle-stimulating hormone measurements, besides karyotype determination and fragile- $X$ premutation syndrome investigation. COMT (Val/Met) genotypes were identified by real time PCR (genotyping TaqMan assay), and the results were statistically analyzed. A statistically significant difference was found in the distribution of COMT genotypes $(p=0.003)$ and alleles $(p=0.015)$ between the POI patients and the control group.

Conclusion: We were able to demonstrate a strong association between the COMT Val/Met polymorphism and the risk of premature ovarian insufficiency in the Brazilian women evaluated. However, further studies in larger populations are necessary to confirm these findings.
\end{abstract}

Keywords: COMT, Estrogen metabolism, Infertility, POI, Polymorphism

\section{Background}

Premature ovarian failure (POF) is a disorder with a complicated clinical presentation and course that is poorly defined by its name. POF is classically defined as a process in which the gradual decline of ovarian function results in failure of folliculogenesis before the age of 40 years, elevated FSH and low estradiol levels [1-3]. However, this definition does not take into account the longitudinal progression towards the final menstrual cycle. A scientifically more accurate term for the disorder is "primary ovarian insufficiency" (POI), which can be appropriately modified to describe the state of the ovarian function [4]. Indeed, the process of ovarian senescence in this condition may

\footnotetext{
* Correspondence: bianca.bianco@hotmail.com

'Center of Human Reproduction and Genetics - Faculdade de Medicina do ABC, Santo André/SP CEP 09060-650, Brazil

${ }^{2}$ Faculdade de Medicina do ABC, Avenida Príncipe de Gales, 821, Santo André/SP CEP: 09060-650, Brasil
}

resemble that of natural menopause, which is preceded by several years by elevated FSH levels and menstrual irregularity [4].

The most common etiologies observed for this condition are chromosomal abnormalities, fragile $\mathrm{X}$ premutations and autoimmune causes. Once these were ruled out, we can think that a non-obvious genetic pathway could be implicated in the disease. Several genes have been identified as being expressed in the ovary and are postulated to play a role in ovarian physiology and in maintaining normal homeostasis in the ovarian cycle. Alterations in these genes can be associated with the development of POI [5]. A recently demonstrated example of that is that mutations in estrogen receptors can affect regulatory pathways and have been reported to be positively associated with the development of POI [6-8]. 
It was demonstrated that the gene COMT (catecholO-methyltransferase - Gene ID: 1312) is expressed in granulosa cells [9], where it acts by processing the estrogen metabolites. The increase of these metabolites can promote cellular atresia, with consequent anovulation. The widely studied Val/Met polymorphism (rs4680) that occurs in COMT is characterized by the substitution of valine for methionine at codon 158, and this substitution results in a less active enzyme form, which in turn promotes an increase of metabolites in patients with the mutated allele [9].

The main estrogens, estrone $\left(E_{1}\right)$ and estradiol $\left(E_{2}\right)$, can suffer oxidative metabolism at different positions, catalyzed by various cytochrome $\mathrm{P} 450$ isoforms. The oxidation produces A-ring metabolites such as catecholestrogens (CEs) by 2-and 4-hydroxylation, and D-ring metabolites by $16 \alpha$-hydroxylation [10]. The metabolism of CEs and $16 \alpha-\mathrm{OH}$-estrogens is catalyzed by phase II metabolic enzymes such as COMT [11], which constitutes a crucial element in estrogen metabolism by regulating the inactivation and elimination of carcinogenic metabolites by converting them into non-carcinogenic methoxyestrogens such as 2-methoxyestradiol $\left(2-\mathrm{ME}_{2}\right)$ and 4-methoxyestradiol $\left(4-\mathrm{ME}_{2}\right)[12,13] .2-\mathrm{ME}_{2}$ is suggested to have a potential physiologic role in follicle homeostasis [5].

Thus, our current hypothesis is based on the fact that COMT converts CEs to $2-\mathrm{ME}_{2}$, and that polymorphisms in the COMT gene could interfere in the concentration of $2 \mathrm{ME}_{2}$, contributing to POI. So, the aim of this study was to determine whether the $\mathrm{Val} / \mathrm{Met}$ genetic variation in the steroid hormone metabolism gene COMT is associated with Premature Ovarian Insufficiency in Brazilian women.

\section{Material and methods Patients}

A total of 216 women were selected to participate in the study. Ninety-six of these women, diagnosed with POI, were recruited from the Human Reproduction and Genetics Center of Faculdade de Medicina do ABC (FMABC), Santo André, SP, Brazil. An important fact about the clinical history of these women is that all of them came to the Center with the wish of achieving pregnancy. All patients were diagnosed in FMABC hospitals, based on two confirmed serum FSH level measurements of $>25 \mathrm{IU} / \mathrm{L}$ before the age of 40 years. The serum FSH levels were measured at two separate time-points within a period of two months. The control group included 120 healthy women who had gone into physiological menopause around 48 years of age (mean $46.3 \pm 1.36 \mathrm{y}$ ), had been fertile, with a normal menstrual history, regular menses (every 25-35 days), no personal or family history of premature or early menopause, and no consumption of oral contraceptives or other hormonal medications at the time of recruitment.

All women underwent a complete clinical examination, along with medical and gynecological history including the reproductive health of the patient's mother, family history, consanguinity, and any other genetic condition in the family, age of menarche and age of menopause. In the patient group, the mean age was $35.7( \pm 5.14)$ years, and the mean age at menopause was $31.5( \pm 6.59)$ years. All patients had normal karyotypes, determined by analyzing 40 metaphases, and normal alleles for the FMR1 gene (implicated in the Fragile-X syndrome). The FMR1 mutation, the main cause of POI, has a high incidence in the world population. The mean FSH serum value was 75.2 $( \pm 40.1) \mathrm{mUI} / \mathrm{mL}$. Patients with a known cause of POI, such as karyotype abnormalities, oophorectomy, chemo or radiotherapy were excluded from the study.

\section{Methods}

\section{DNA extraction}

Peripheral blood was collected from each patient and control in an EDTA-containing tube. Genomic DNA was extracted from peripheral blood lymphocytes, using the salting-out procedures described by Lahiri \& Nurnberger [14]. Clinical data and peripheral blood samples were only collected after explaining the objectives of the study and obtaining a signed informed consent form, as approved by the Faculdade de Medicina do ABC ethics committee (process no. 184/2007).

\section{COMT genotyping}

Detection of the COMT Val/Met (G/Val; A/Met) polymorphism was performed using TaqMan PCR. TaqMan primers and probes are commercially available and were purchased from Applied Biosystems ${ }^{\circ}$ (Foster City, CA, EUA) (rs4680, C_25746809_50). The assays were performed with TaqMan Universal Master Mix, using $50 \mathrm{ng}$ of DNA per reaction. The PCR conditions were as recommended by the manufacturer: 40 denaturation cycles at $95^{\circ} \mathrm{C}(15 \mathrm{sec})$, and annealing/extension at $60^{\circ} \mathrm{C}(1 \mathrm{~min})$. The reactions were performed on a Rotor gene 6000 realtime PCR platform (Corbett, Mortlake, New South Wales, Australia).

\section{Statistical analysis}

The chi-square and the logistic binary regression tests were performed to compare the genotype frequencies (rare homozygous, heterozygous and common homozygous), odds ratios (OR), and confidence intervals (CI). The analyses were made using the SPSS 18.0 (SPSS, Inc., Chicago, IL, USA) program. All $p$-values were two-tailed, and $95 \%$ confidence intervals (CIs) were calculated. A $p$-value $<0.05$ was considered statistically significant. 


\section{Results}

We found a differential distribution of genotypes and alleles between the studied groups. The GG (Val/Val), GA (Val/Met) and AA (Met/Met) genotype frequencies of the COMT polymorphism in the POI group were $9.4 \%$ (9/96), 52.1\% (50/960) and 38.5\% (37/96), respectively, while in the control group they were $27.5 \%(33 / 120), 39.1 \%$ $(47 / 120)$ and $33.3 \%(40 / 120)(\mathrm{p}=0.003)$, respectively. According to the allelic distribution, allele $\mathrm{G}$ and $\mathrm{A}$ were present, respectively, in $35.4 \%$ and $64.5 \%$ of the POI group, and in $47.0 \%$ and $52.9 \%$, respectively, of the control group, showing a positive statistical correlation between POI and allele A ( $\mathrm{p}=0.015, \mathrm{OR}=1.62,95 \% \mathrm{CI}=$ 1.10-2.39) (Table 1). Both the POI and the control group were in Hardy-Weinberg equilibrium.

\section{Discussion}

The enzyme COMT is ubiquitously found in various mammalian tissues, with high levels in the liver, kidney, endometrium, breast and granulosa cells $[15,16]$. A common polymorphism, G/A in codon 158 of COMT, leads to a substitution of a valine for a methionine in the gene product, which is linked to low COMT activity, with an up to 4-fold decrease in activity in red blood cells and liver [16]. It has been hypothesized that reduced COMT activity may increase the risk of hormone-dependent diseases by enhancing the serum and tissue levels of estradiol, as well as by the accumulation of catecholestrogens and the subsequent oxidative DNA damage [17].

Several association studies in POI candidate genes have been widely used in the search for susceptibility alleles, but only few definitive associations have been established. These inconsistencies in results probably reflect an actual variation in the underlying association between populations studied and the low penetrance of mutations in these multigenic pathways [18]. In the present study, the patient group was homogeneous and especially selected by the presence of infertility, defined according to the minimum propedeutics of the infertile couple. In addition, all patients were investigated as to other causes of POI, such as chromosome aberrations, and positive findings were used as exclusion criteria.

To our best knowledge, this is the first study that correlates COMT polymorphism and premature ovarian insufficiency. Here, we found a positive association of allele
A of the studied polymorphism with POI, reflecting on the genotype, as we observed a high frequency of heterozygous and mutated homozygous $(\mathrm{p}=0.003)$ and allelic distribution $(\mathrm{p}=0.015)$. The allele acts in a dominant mode. We suppose that it may produce increased damage to ovarian cells, leading to POI.

The estrogen oxidative DNA damage effect has previously been shown to affect both female and male reproduction $[19,20]$. The risk of oxidative damage and lipid peroxidation was found to be especially high in steroid-synthesizing tissues, because, in addition to oxidative phosphorylation, they use molecular oxygen. Indeed, it has been shown that free radicals inhibit steroidogenesis by interfering with cholesterol transport to the mitochondria and/or the catalytic function of P450 enzymes, which leads to an increase of lipid peroxidation and to the decline of the antioxidant barrier. Considering males, all these changes can alter the testicular cells, including spermatozoa and, therefore, the sperm production, leading to an alteration in male fertility [21]. In females, it can determine cellular apoptosis, corpus luteum regression and follicular atresia $[19,22]$.

Salih et al. [5] proposed that the metabolite 2- $\mathrm{ME}_{2}$ has a potential physiological role in follicle homeostasis: under normal conditions, its level is low in early folliculogenesis, rising (probably to the inhibitory range) with the augmented $\mathrm{E}$ production in the fully developed dominant follicle. Modulation of COMT activity and, therefore, the concentration of $2-\mathrm{ME}_{2}$ might be part of the ovarian physiological apparatus. Thus, a pathologic alteration of COMT could lead to a major perturbation of folliculogenesis.

In PCOS (Polycystic Ovary Syndrome), catechol Omethyltransferase overexpression and increased levels of $2-\mathrm{ME}_{2}$ in ovarian granulosa cells represent a mechanism leading to abnormalities of steroidogenesis, follicular arrest, and anovulation [5]. We propose that the opposite occurs in POI. Here, we found that most of the POI patients presented an increased incidence of the lowactivity COMT allele, promoting decreased formation of $2-\mathrm{ME}_{2}$.

As suggested by Salih et al. [5], we believe that disturbed levels of $2-\mathrm{ME}_{2}$ could be associated with increased follicular depletion, eventually leading to follicular arrest. This disturbed pathway seems to be an important

Table 1 Genotype and allele frequencies of the COMT Val/Met polymorphism in POI patients and a control group

\begin{tabular}{|c|c|c|c|c|c|c|c|c|c|c|c|c|}
\hline \multirow{2}{*}{$\begin{array}{l}\text { Population } \\
\text { studied }\end{array}$} & \multirow[t]{2}{*}{$\mathrm{n}$} & \multicolumn{4}{|c|}{ COMT G/A genotypes } & \multicolumn{4}{|c|}{ COMT Alleles } & \multicolumn{2}{|c|}{ Dominant model } & \multirow[t]{2}{*}{$\mathbf{p}$} \\
\hline & & GG (\%) & GA (\%) & AA (\%) & $\mathrm{p}$ & G (\%) & A (\%) & $\mathrm{p}$ & OR $(95 \% \mathrm{Cl})$ & GG & $\mathrm{GA}+\mathrm{AA}$ & \\
\hline POF patients* & 96 & $9(9.4)$ & $50(52.1)$ & $37(38.5)$ & 0.003 & $68(35.4)$ & $113(58.8)$ & 0.015 & $1.62(1.10-2.39)$ & 9 & 87 & 0.0008 \\
\hline Control group* & 120 & $33(27.5)$ & $47(39.2)$ & $40(33.3)$ & & $113(47.1)$ & $127(52.9)$ & & & 33 & 87 & \\
\hline
\end{tabular}

*Sample groups are in Hardy Weinberg equilibrium. 
mechanism associated with Premature Ovarian Insufficiency in Brazilian women. However, further studies in larger sample sets are needed to confirm these findings.

\section{Competing interests}

None of the authors has any conflict of interest to disclose.

\section{Authors' contribution}

EBC participated in patients' evaluation and selection and study design; MS, CP and EAK participated in samples preparation, molecular genetics studies and statistical analysis; BB and CPB participated in manuscript design and DMC participated in the conception of the idea, supervision of the research and manuscript design. All authors read and approved the final manuscript.

\section{Acknowledgments}

The authors would like to thank CNPq for Research grant provided to the study ( 470333/2013-8), for student scholarship granted to Erika Azuma Kaiaky (PIBIC), and productivity grant provided to Denise Maria Christofolini (301242/2013-5), Bianca Bianco (300825/2013-7) and Caio Parente Barbosa (300816/2012-0)

Received: 11 February 2014 Accepted: 21 April 2014

Published: 2 May 2014

\section{References}

1. Santoro N: Mechanisms of premature ovarian insufficiency. Ann Endocrinol 2003, 64:87-92.

2. Coulam CB, Adamson SC, Annegers JF: Incidence of premature ovarian failure. Obstet Gynecol 1986, 67(4):604-606.

3. Kalantaridou SN, Davis SR, Nelson LM: Premature ovarian failure. Endocrinol Metab Clin North Am 1998, 27(4):989-1006

4. Welt CK: Primary ovarian insufficiency: a more accurate term for premature ovarian insufficiency. Clin Endocrinol (Oxf) 2008, 68:499-509.

5. Salih SM, Salama SA, Fadl AA, Nagamani M, Al-Hendy A: Expression and cyclic variations of catechol-0-methyl transferase in human endometrial stroma. Fertil Steril 2008, 90:789-797.

6. Cordts EB, Santos AA, Peluso C, Bianco B, Barbosa CP, Christofolini DM: Risk of premature ovarian failure is associated to the Pvull polymorphism at estrogen receptor gene ESR1. J Assist Reprod Genet 2012, [Epub ahead of print].

7. Liu L, Tan R, Cui Y, Liu J, Wu J: Estrogen receptor a gene (ESR1) polymorphisms associated with idiopathic premature ovarian failure in Chinese women. Gynecol Endocrinol 2012, [Epub ahead of print].

8. M'Rabet N, Moffat R, Helbling S, Kaech A, Zhang H, de Geyter C: The CC-allele of the Pvull polymorphic variant in intron 1 of the a-estrogen receptor gene is significantly more prevalent among infertile women at risk of premature ovarian aging. Fertil Steril 2012, 98(4):965-972. e1-5.

9. Lachman HM, Papolos DF, Saito T, Yu YM, Szumlanski CL, Weinshilboum RM: Human catechol-O-methyltransferase pharmacogenetics: description of a functional polymorphism and its potential application to neuropsychiatric disorders. Pharmacogenetics 1996, 6(3):243-250.

10. Zhu BT, Conney AH: Is 2-methoxyestradiol an endogenous estrogen metabolite that inhibits mammary carcinogenesis? Cancer Res 1998, $58: 2269-2277$

11. Hevir N, Sinkovec J, Rižner TL: Disturbed expression of phase I and phase II estrogen-metabolizing enzymes in endometrial cancer: lower levels of CYP1B1 and increased expression of S-COMT. Mol Cell Endocrinol 2011 331(1):158-167.

12. Cavalieri E, Rogan $E$ : Catechol quinones of estrogens in the initiation of breast, prostate, and other human cancers: keynote lecture. Ann N Y Acad Sci 2006, 1089:286-301.

13. Delort L, Satih S, Kwiatkowski F, Bignon YJ, Bernard-Gallon DJ: Evaluation of breast cancer risk in a multigenic model including low penetrance genes involved in xenobiotic and estrogen metabolisms. Nutr Cancer 2010, 62:243-251.

14. Lahiri DK, Nurnberger JI Jr: A rapid non-enzymatic method for the preparation of HMW DNA from blood for RFLP studies. Nucleic Acids Res 1991, 19:5444.

15. Weisz J, Clawson GA, Creveling CR: Biogenesis and inactivation of catecholestrogens. Adv Pharmacol 1998, 42:828-833.

16. Weinshilboum RM, Otterness DM, Szumlanski CL: Methylation pharmacogenetics: catechol O-methyltransferase, thiopurine methyltransferase, and histamine $\mathrm{N}$-methyltransferase. Annu Rev Pharmacol Toxicol 1999, 39:19-52.

17. Huber JC, Schneeberger C, Tempfer CB: Genetic modelling of the estrogen metabolism as a risk factor of hormone-dependent disorders. Maturitas 2002, 42:1-12.

18. Colhoun HM, McKeigue PM, Davey SG: Problems of reporting genetic associations with complex outcomes. Lancet 2003, 361:865-872.

19. Martimbeau S, Tilly JL: Physiological cell death in endocrine-dependent tissues: an ovarian perspective. Clin Endocrinol (Oxf) 1997, 46:241-254.

20. Watson CE, Gauthier SY, Davies PL: Structure and expression of the highly repetitive histone $\mathrm{H} 1$-related sperm chromatin proteins from winter flounder. Eur J Biochem 1999, 262:258-267.

21. Hamden K, Silandre D, Delalande C, Elfeki A, Carreau S: Protective effects of estrogens and caloric restriction during aging on various rat testis parameters. Asian J Androl 2008, 10:837-845.

22. Murdoch WJ: Inhibition by oestradiol of oxidative stress-induced apoptosis in pig ovarian tissues. J Reprod Fertil 1998, 114:127-130.

doi:10.1186/1757-2215-7-47

Cite this article as: Cordts et al: COMT polymorphism influences decrease of ovarian follicles and emerges as a predictive factor for premature ovarian insufficiency. Journal of Ovarian Research 2014 7:47.

\section{Submit your next manuscript to BioMed Central and take full advantage of:}

- Convenient online submission

- Thorough peer review

- No space constraints or color figure charges

- Immediate publication on acceptance

- Inclusion in PubMed, CAS, Scopus and Google Scholar

- Research which is freely available for redistribution 